Elsevier

TOXLett. 1404

\title{
MUTAGENICITY IN SALMONELLA ASSAYS OF CYCLOHEXANE EPOXIDE DERIVATIVES
}

(Cyclohexane epoxides; structure-mutagenicity relationships; substituent effects on mutagenicity; comparative Ames spot-test mutagenicity and toxicity)

S.W. FRANTZ ${ }^{b}$, E. VAN DEN EECKHOUT ${ }^{c}$, J.E. SINSHEIMER ${ }^{a}$, M. YOSHIHARA* and M. KOREEDA*

College of Pharmacy, and *Department of Chemistry, University of Michigan, Ann Arbor, MI 48109 (U.S.A.)

(Received December 17th, 1984)

(Accepted March 13th, 1985)

\section{SUMMARY}

15 Cyclohexane epoxide derivatives were synthesized and compared for direct mutagenicity and bacterial toxicity using Salmonella typhimurium strain TA100 in the liquid suspension and spot-test version of the Ames procedure. While no general correlations could be established for position and stereochemistry of the hydroxylated derivatives, an increase in mutagenicity was noted for the presence of electron-withdrawing groups and unsaturation in conjugation with the oxirane groups.

\section{INTRODUCTION}

Direct mutagenic activity of epoxides in the Ames test and other short-term mutagenicity assays is well established and has been summarized in 2 recent extensive reviews on the relationship of epoxide metabolism and genetic interactions of toxicity $[1,2]$. The potential risk to human health from epoxides and, indirectly, from their olefin precursors has been established largely from research which has

\footnotetext{
${ }^{a}$ To whom correspondence should be addressed.

b Present address: Mammalian and Environmental Toxicology Research Laboratory, Dow Chemical U.S.A. Midland, MI 48640, U.S.A.

' On leave from Laboratoria voor Farmaceutische Chemie en Ontleding van Geneesmiddelen, Rijksuniversiteit Gent, Harelbekestraat 72, B-9000 Gent, Belgium.
}

Abbreviations: BP, benzo[a]pyrene; PAH, polycyclic aromatic hydrocarbons. 
identified an epoxide metabolite as the ultimate mutagenic species for several polycyclic aromatic hydrocarbons (PAH). One of the most thoroughly investigated of the PAH compounds is benzo[a]pyrene (BP), and numerous reports on the metabolic fate of this molcculc, as well as testing with model compounds, have implicated the diol epoxides as the ultimate mutagenic/carcinogenic metabolites [3]. However, literature evidence for the mutagenic activity of less complex ring systems by comparison is not so extensive. Weak to moderate Ames test mutagenicity has been reported by Jung et al. [4] for 17 cyclohexane epoxides.

Similarly, this laboratory has investigated the mutagenic potential of simple ring epoxide systems [5,6]. Our present work has focused on the influence of mono- and disubstituted groups on the mutagenic response of 1,2-epoxycyclohexanes on Salmonella strain TA100. Results are reported here for 15 compounds using both the spot test and liquid suspension versions of the Ames test [7]. These observations are part of ongoing work in which we are examining substituent group electronic influences on cyclic oxirane mutagenicity, as well as the effects on mutagenic response of molecular planarity and rigidity imparted by olefinic moieties in more complex fused-ring oxiranes.

\section{MATERIALS AND METHODS}

The epoxides 2,4 , and 11 were prepared from their corresponding olefins by direct oxidation with vanadyl acetylacetonate in benzene, by the method of Sharpless and Michaelson [8] and compounds $5-7$ and 12 by oxidation with $m$ chloroperoxybenzoic acid in dichloromethane, by the method of Schwartz and Blumbergs [9]. Compounds $1,3,8,9$ and 10 were prepared via their benzoyl derivatives by the $m$-chloroperoxybenzoic acid method, followed by base hydrolysis. Compounds $1-4$ and $8-13$ were purified first via silica gel flash column chromatography followed by either distillation or recrystallization. HPLC with a silica dichloromethane-hexane system was used for the purification of compounds 5-7. Epoxides 13-15 were synthesized and their absolute configurations established by the method published earlier by Koreeda and Yoshihara [4].

Purity of the epoxides was estimated to be greater than $99 \%$ by GC, or by HPLC and $360 \mathrm{MHz}{ }^{1} \mathrm{H}$ and $90 \mathrm{MHz}{ }^{13} \mathrm{C}$ nmr spectroscopy. Stereochemical assignments, where applicable, are based on ${ }^{1} \mathrm{H} \mathrm{nmr}$ analysis involving detailed spin-spin decoupling experiments.

Culture media were prepared and strain TA100 was routinely screened for its proper characteristics, as described by Ames [7]. Cultures were grown by inoculating nutrient broth with the tester strain the night before the test, and leaving it to rest overnight in a Nephelo culture flask with a $1.2 \mathrm{~cm}$ side arm. The culture was then shaken in a water bath at $37^{\circ} \mathrm{C}$ until it reached an absorbance at $560 \mathrm{~nm}$ of 0.78-0.85. In our use of the spot test [7], $0.1 \mathrm{ml}$ of bacteria (strain TA100) was added to top agar containing minimal histidine-biotin, and compounds dissolved in 
$0.01 \mathrm{ml}$ of DMSO were delivered to a $0.633 \mathrm{~cm}$ diameter sterile filter disc (penicillin assay disc, Schleicher and Schuell, Keene, $\mathrm{NH}$ ) which had been placed in the center of the agar plate subsequent to hardening of the top agar overlay. After incubation at $37^{\circ} \mathrm{C}$ for $48 \mathrm{~h}$, the radius $\left(R_{\mathrm{mut}}\right)$ from the center of the disc to the outer edge of the zone of mutagenicity was measured. Toxicity, when present, was measured as the radius $\left(\mathbf{R}_{\text {tox }}\right)$ from the center of the disc to the outer edge of a transparent zone around the disc in which all bacterial growth, including background lawn, had been eliminated.

In the liquid suspension procedure for the Ames test [7], the epoxides in $0.1 \mathrm{ml}$ of DMSO were added to $1.5 \mathrm{ml}$ of bacterial culture and $0.5 \mathrm{ml}$ of $0.1 \mathrm{M}$ phosphate buffer ( $\mathrm{pH} 7.4$ ) in a sterile $3.5-\mathrm{ml}$ tube, which was capped and incubated for $2 \mathrm{~h}$ at $37^{\circ} \mathrm{C}$ in a water bath with shaking. After incubation, the tubes were centrifuged for $10 \mathrm{~min}$ at $9000 \times g$ and the supernatant removed. The pellet was resuspended in $0.1 \mathrm{M}$ phosphate buffer $(0.815 \mathrm{ml})$ and $0.2-\mathrm{ml}$ aliquots were removed and added to $2.9 \mathrm{ml}$ of top agar containing minimal histidine-biotin, then plated in 4 replicate plates per dose. These plates were incubated for $48 \mathrm{~h}$ at $37^{\circ} \mathrm{C}$. Colony counting was performed manually. Bacterial toxicity was determined by preparing $10^{-5}$ dilutions in 3 sequential dilutions from $0.01 \mathrm{ml}$ of the original bacterial suspensions, as used with compounds present for the mutagenicity tests. 4 Replicate tests per dose were conducted, with $0.1 \mathrm{ml}$ of the $10^{-5}$ dilution platcd onto minimal agar plates to which $0.1 \mathrm{ml}$ of a $0.1 \mathrm{M}$ histidine solution had been added. Comparisons of bacterial counts on test compound plates with bacterial counts on control plates (containing only solvent) were used to determine $\%$ growth inhibition.

\section{RESULTS AND DISCUSSION}

Preliminary tests have indicated that for most of the present series of cyclohexane epoxide compounds there is a problem of toxicity interfering with the establishment of relative mutagenicity. This was previously described for the unsubstituted cycloaliphatic epoxides [6] and is shown in Table I for the Ames [7] liquid suspension mutagenicity and toxicity results for compounds $1-12$. Toxicity to Salmonella strain TA100, which accompanied the high doses required to demonstrate mutagenicity, prevented the establishment of meaningful dose-response ranges for most of the compounds under investigation. Even for one of the more mutagenic compounds, 4-cyanocyclohexane-1,2-epoxide (7), a meaningful dose-response relationship could only be cstablished up to about $20 \mu \mathrm{mol}$ per incubation volume before toxicity effects were evident. However, at this dose, in the liquid suspension test (Table I), compounds 5 and 6 showed $100 \%$ toxicity and compounds such as 8,10 and 11 , where toxicity was not indicated at this level, showed little mutagenicity above background. Therefore, the spot test version of the Ames et al. [7] method was selected to compare the mutagenicity of these cyclohexane epoxide derivatives, since this version of the Ames test is capable of separating zones of 
TABLE I

MUTAGENICITY AND TOXICITY OF CYCLOHEXANE EPOXIDE DERIVATIVES IN TA 100

\begin{tabular}{|c|c|c|c|c|c|c|}
\hline \multirow[t]{2}{*}{ Compounds } & \multicolumn{3}{|c|}{ Liquid suspension } & \multicolumn{3}{|l|}{ Spot test } \\
\hline & $\begin{array}{l}\text { Dose } \\
(\mu \mathrm{mol} / \\
\text { plate })\end{array}$ & $\begin{array}{l}\text { Revert- } \\
\text { ants/ } \\
\text { platc }^{\mathrm{a}}\end{array}$ & 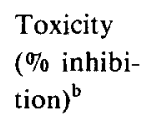 & $\begin{array}{l}\text { Dose } \\
\text { ( } \mu \text { moles/ } \\
\text { platc) }\end{array}$ & $\begin{array}{l}R_{\text {mut }}{ }^{c} \\
(\mathrm{~cm})\end{array}$ & $\begin{array}{l}\mathrm{R}_{\text {tox }}{ }^{\mathrm{d}} \\
(\mathrm{cm})\end{array}$ \\
\hline 1 & 50 & $111 \pm 26$ & 86 & 30 & 1.5 & 0 \\
\hline 2 & 50 & $143 \pm 13$ & 38 & 30 & 1.7 & 0 \\
\hline 3 & 50 & $153 \pm 24$ & 31 & 30 & 1.8 & 0 \\
\hline 4 & 50 & $119 \pm 12$ & 9 & 30 & 1.9 & 0 \\
\hline 5 & 30 & $N^{e}$ & 100 & 20 & 2.9 & 1.2 \\
\hline 6 & 30 & NR & 100 & 25 & 2.3 & 0.8 \\
\hline 7 & 30 & $219 \pm 27$ & 63 & 30 & 2.3 & 0 \\
\hline 8 & $\begin{array}{l}30 \\
50\end{array}$ & $\begin{array}{l}66 \pm 24 \\
64 \pm 21\end{array}$ & $\begin{array}{l}0 \\
0\end{array}$ & 27 & 2.0 & 0.5 \\
\hline 9 & 30 & $5 \pm 6$ & 11 & 58 & $B G^{f}$ & 0.4 \\
\hline & 50 & $1 \pm 9$ & 72 & 87 & 1.8 & 0.5 \\
\hline 10 & 30 & $25 \pm 18$ & 0 & & & \\
\hline & 50 & $58 \pm 11$ & 42 & 19 & BG & 0.6 \\
\hline 11 & 30 & $22 \pm 4$ & 0 & & & \\
\hline & 50 & $6 \pm 6$ & 41 & 54 & BG & 0.4 \\
\hline 12 & 30 & $186 \pm 20$ & 0 & & & \\
\hline & 50 & $364 \pm 23$ & 35 & 36 & 1.8 & 0.4 \\
\hline
\end{tabular}


TABLE I (CONTINUED)

MUTAGENICITY AND TOXICITY OF CYCLOHEXANE EPOXIDE DERIVATIVES IN TA 100

\begin{tabular}{|c|c|c|c|c|c|c|}
\hline \multirow[t]{2}{*}{ Compounds } & \multicolumn{3}{|c|}{ Liquid suspension } & \multicolumn{3}{|l|}{ Spot test } \\
\hline & $\begin{array}{l}\text { Dose } \\
(\mu \mathrm{mol} / \\
\text { plate })\end{array}$ & $\begin{array}{l}\text { Revert- } \\
\text { ants } \\
\text { plate }\end{array}$ & $\begin{array}{l}\text { Toxicity } \\
\text { (\% inhibi- } \\
\text { tion) })^{b}\end{array}$ & $\begin{array}{l}\text { Dose } \\
\text { (amoles/ } \\
\text { plate) }\end{array}$ & $\begin{array}{l}\mathrm{R}_{\mathrm{mui}}{ }^{\mathrm{c}} \\
(\mathrm{cm})\end{array}$ & $\begin{array}{l}R_{\text {tox }}{ }^{d} \\
(\mathrm{~cm})\end{array}$ \\
\hline 13 & & & & 16 & 1.2 & 0.4 \\
\hline 14 & & & & 20 & 1.4 & 0.5 \\
\hline 15 & & & & 30 & 1.5 & 0.8 \\
\hline
\end{tabular}

Mean of 4 determinations \pm standard deviation with background counts (plates with $0.1 \mathrm{ml}$ DMSO only) subtracted where standard deviation $=\sqrt{\mathrm{SD}_{\text {background }}^{2}+\mathrm{SD}_{\text {determination }}^{2}}$

bInhibition of growth on nutrient agar plates of a $10^{-5}$ dilution of the culture used for mutagenicity at the doses tested for mutagenicity and compared to positive controls in which only $0.1 \mathrm{ml}$ DMSO is added.

${ }^{c} R_{\text {mu }}$ is the radius to the furthest edge of the revertant zone measured from the center of the filter disc.

${ }^{d} R_{10 x}$ is the radius of cell-killing immediately around the filter disc.

'No response observed due to toxicity.

${ }^{f}$ Background counts only with no detectable zone of revertant colonies.

mutagenicity from zones of toxicity. The objective was to gain information as to the relative mutagenicity and bacterial toxicity in TA100 of these compounds as well as to serve as a guide for candidates for synthesis in future structure-mutagenicity studies. Mutagenicity and bacterial toxicity results for the spot test are listed in Table I.

Compound 14, cyclohexene-trans-3,4:5,6-diepoxide, was also studied by Jung et al. [4] and therefore served as a point of comparison in the present series to results obtained by the standard plate incorporation procedure. A mutagenic reponse of 78 revertant colonies per $\mu \mathrm{mol}$ above background was reported by these workers for this compound. Thus, the present series of compounds is, at most, only moderately mutagenic. This is in general agreement with the literature for related fused-ring epoxides $[4,6]$. Certainly, none of these simple ring epoxides even approached the mutagenicity of the active metabolites of BP as previously described by Wood et al. [11].

It was of interest to determine whether the position and stereochemistry of hydroxyl groups relative to the epoxide moiety affects mutagenicity. Wood et al. [11] have shown that mutagenicity in the Ames test is greater for the $7 \beta, 8 \alpha$ dihydroxy-9 $\beta, 10 \beta$-epoxy-7,8,9,10-tetrahydrobenzo[a]pyrene (16) metabolite of BP 
than for isomer 17 . Also, the greater activity of isomer $16 \mathrm{vs.} \mathrm{isomer} 17$ during nucleophilic attack has been explained $[12,13]$ on the basis of intramolecular hydrogen bonding being possible where the hydroxyl group at carbon 7 is on the same side of the ring as the epoxide (syn) as compared to the anti arrangement in compound 17 .

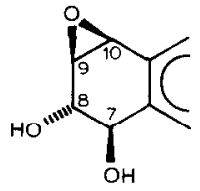

16

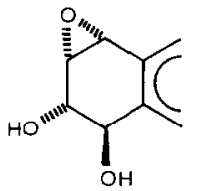

17

The results for the mono-substituted cyclohexane derivatives are not definitieve in this regard, as there appears to be little difference in mutagenicity in either the liquid suspension or spot test results (Table I) for the mono-hydroxy compounds (1-4) when the hydroxy group is in the 3 or 4 position or is anti or syn in relationship to the epoxide. However, for the 3,4-diol epoxides, the syn-4-hydroxy compound 8 is indeed more mutagenic than the anti arrangement in compound 9 in both the spot test and liquid suspension tests. Recently Turchi et al. [14] have also tested compound 9 and found it to lack mutagenicity in a Saccharomyces cerevisiae system. With the 4,5-diol epoxides, it is of interest that the syn, anti compound 12 is definitely more mutagenic in both tests than compound 11 , in which all groups are on the same side of the ring.

Electron-withdrawing substituents appear to increase mutagenicity, especially as indicated by compounds 5,6 and 13 . Also, the mutagenicity of compounds 13-15 is consistent with the observations of Jung et al. [4] and Turchi et al. [14] that unsaturation in conjugation with epoxy groups increases mutagenicity. The mutagenicity of hydroxy cpoxide derivatives of tetrahydronaphthalene should be of interest in an extension of the present studies, in that these would retain the conjugation of unsaturation to the epoxide, have an electron-withdrawing component in the benzo group per se and may be useful in clarifying the effect of the arrangement of the hydroxyl groups on mutagenicity.

\section{ACKNOWLEDGEMENTS}

The authors wish to express their appreciation to Dr. Bruce Ames, University of California at Berkeley, for supplying the Salmonella strain TA100. This research was supported by Grant Nos. R01 ES03345 from the National Institute of Environmental Health Sciences and R0l CA 25185 from the National Cancer Institute, DHHS. 


\section{REFERENCES}

1 M.M. Manson, Epoxides-is there a health problem? Brit. J. Ind. Med., 37 (1980) 317-336.

2 L. Ehrenberg and S. Hussain, Genetic toxicity of some important epoxides, Mutat. Res., 86 (1981) 1-113.

3 H.V. Gelboin and P.O.P. Ts'o, (Eds.), Polycyclic hydrocarbons and cancer, Vols. 1 and 2, Academic Press, New York, 1978.

4 R. Jung, D. Beermann, H.R. Glatt and F. Oesch, Mutagenicity of structurally related oxiranes, derivatives of benzene and its hydrogenated congeners, Mutat. Res., 81 (1981) 11-19.

5 D.R. Wade, S.C. Airy and J.E. Sinsheimer, Mutagenicity of aliphatic epoxides, Mutat. Res., 58 (1978) 217-223.

6 S.W. Frantz and J.E. Sinsheimer, Bacterial mutagenicity and toxicity of cycloaliphatic epoxides, Mutat. Res., 90 (1981) 67-78.

7 B.N. Ames, J. McCann, and E. Yamasaki, Methods for detecting carcinogens and mutagens with the Salmonella/mammalian-microsome mutagenicity test, Mutat. Res., 31 (1975) 347-364.

8 K.B. Sharpless and R.C. Michaelson, High stereo and regioselectivities in the transition metalcatalyzed epoxidations of olefinic alcohol by tert-butyl hydroperoxide, J. Amer. Chem. Soc., 95 (1973) 6136-6137.

9 N.M. Schwartz and J.H. Blumbergs, Epoxidations with $m$-chloroperbenzoic acid, J. Org. Chem., 29 (1964) 1976-1979.

$10 \mathrm{M}$. Koreeda and M. Yoshihara, The absolute configuration of anti-benzene and anti-napthalene 1,2:3,4-dioxides, J. Chem. Soc. Chem. Comm., (1981) 974-976.

11 A.W. Wood, P.G. Wislocki, R.L. Chang, W. Levin, A.Y.H. Lu, H. Yagi, O. Hernandez, D.M. Jerina and A.H. Conney, Mutagenicity and cytotoxicity of benzo(a)pyrene benzo-ring epoxides, Cancer. Res., 36 (1976) 3358-3366.

12 P.B. Hulbert, Carbonium ion as ultimate carcinogen of polycyclic aromatic hydrocarbons, Nature, 256 (1975) 146-148.

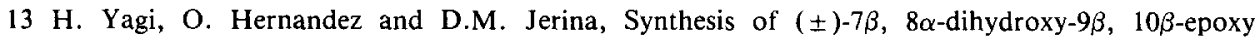
1-7,8,9,10-tetrahydrobenzo[a]pyrene, a potential metabolite of the carcinogen benzo[a]pyrene with stereochemistry related to the antileukemic triptolides, J. Amer. Chem. Soc., 97 (1975) 3185-3192.

14 G. Turchi, C. Bauer, G. Bronzetti, L. Citti, C. Corsi, G.F. Fassina, P.G. Gervasi, A. Lippi, R. Nieri, A. Abbondandolo, G. Berti and E. Mastrorilli, Mutagenicity of 3 structurally related epoxides, with defined stereochemical configuration, in Saccharomyces cerevisiae and in V79 Chinese hamster cells, Mutat. Res., 117 (1983) 213-224. 